\title{
Silver Removal Process Development for the MEO Cleanout
}

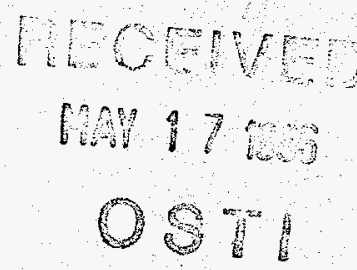

Peter C. Hsu, Zoher Chiba, Bruce J. Schumacher, Laura C. Murguia, and Martyn G. Adamson

February 1996

This is an informal report intended primarily for internal or limited external distribution. The opinions and conclusions stated are those of the author and may. or may not be those of the Laboratory.

Work performed under the auspices of the U.S. Department of Energy by the Lawrence Livermore National Laboratory under Contract W-7405-Eng-48. 


\section{DISCLAIMER}

This document was prepared as an account of work sponsored by an agency of the United States Government. Neither the United States Government nor the University of California nor any of their employees, makes any warranty, express or implied, or assumes any legal liability or responsibility for the accuracy, completeness, or usefulness of any information, apparatus, product, or process disclosed, or represents that its use would not infringe privately owned rights. Reference herein to any specific commercial product, process, or service by trade name, trademark; manufacturer, or otherwise, does not necessarily constitute or imply its endorsement, recommendation, or favoring by the United States Government or the University of California. The views and opinions of authors expressed herein do not necessarily state or reflect those of the United States Government or the University of California, and shall not be used for advertising or product endorsement purposes.

This report has been reproduced directly from the best available copy.

Available to DOE and DOE contractors from the Office of Scientific and Technical Information P.O. Box 62, Oak Ridge, TN 37831

Prices available from (615) 576-8401, FTS 626-8401

Available to the public from the

National Technical Information Service

U.S. Department of Commerce 5285 Port Royal Rd., Springfield, VA 22161 


\section{DISCLATMER}

Portions of this document may be illegible in electronic image produets. Images are produced from the best avallable original document. 


\title{
Silver Removal Process Development for the MEO Cleanout*
}

\author{
Peter C. Hsu, Zoher Chiba, Bruce J. Schumacher, \\ Laura C. Murguia, and Martyn G. Adamson \\ Lawrence Livermore National Laboratory \\ Livermore, CA 94550
}

\section{Introduction}

The Mediated Electrochemical Oxidation (MEO) system is an aqueous process which treats low-level mixed wastes by oxidizing the organic components of the waste into carbon dioxide and water. As MEO system continues to run, dissolved ash and radionuclides slowly accumulate in the anolyte and must be removed to maintain process efficiency. At such time, all of the anolyte is pumped into a still feed tank, and the silver ions need to be removed before sending the solution to a thin-film evaporator for further concentration (Reference 1). The efficiency of removing silver ions in the solution needs to be high enough such that the residual silver sent to Final Forms would be less than $1 \%$ wt. (Reference 2). The purpose of this work is to develop an efficient process to remove silver ions during the MEO cleanout and to demonstrate the capability of centrifugation for separating small silver chloride particles from the solution. This development work includes lab scale experiments and bench scale tests. This report summarizes the results.

\section{Lab Scale Experiments}

\section{A. Chemistry}

Hydrochloric acid is an effective reagent to remove silver ions in the anolyte as shown by the chemical reaction below:

$$
\mathrm{Ag}^{+}+\mathrm{H}^{+}+\mathrm{NO}_{3}^{-}+\mathrm{Cl}^{-} \ldots . .-\mathrm{AgCl}_{(\mathrm{s})}+\mathrm{H}^{+}+\mathrm{NO}_{3}^{-}
$$


The concentrations of silver ions and nitric acid in the anolyte solution are about $0.4-0.5 \mathrm{M}$ and $8 \mathrm{M}$, respectively. The concentration of dissolved ash in the anolyte before a cleanout is required is about $10 \%$ wt.

B. Lab Scale Experiments

Fig. 1 describes the procedure for lab scale experiments.

Fig. 1 Lab Scale Silver Removal Process

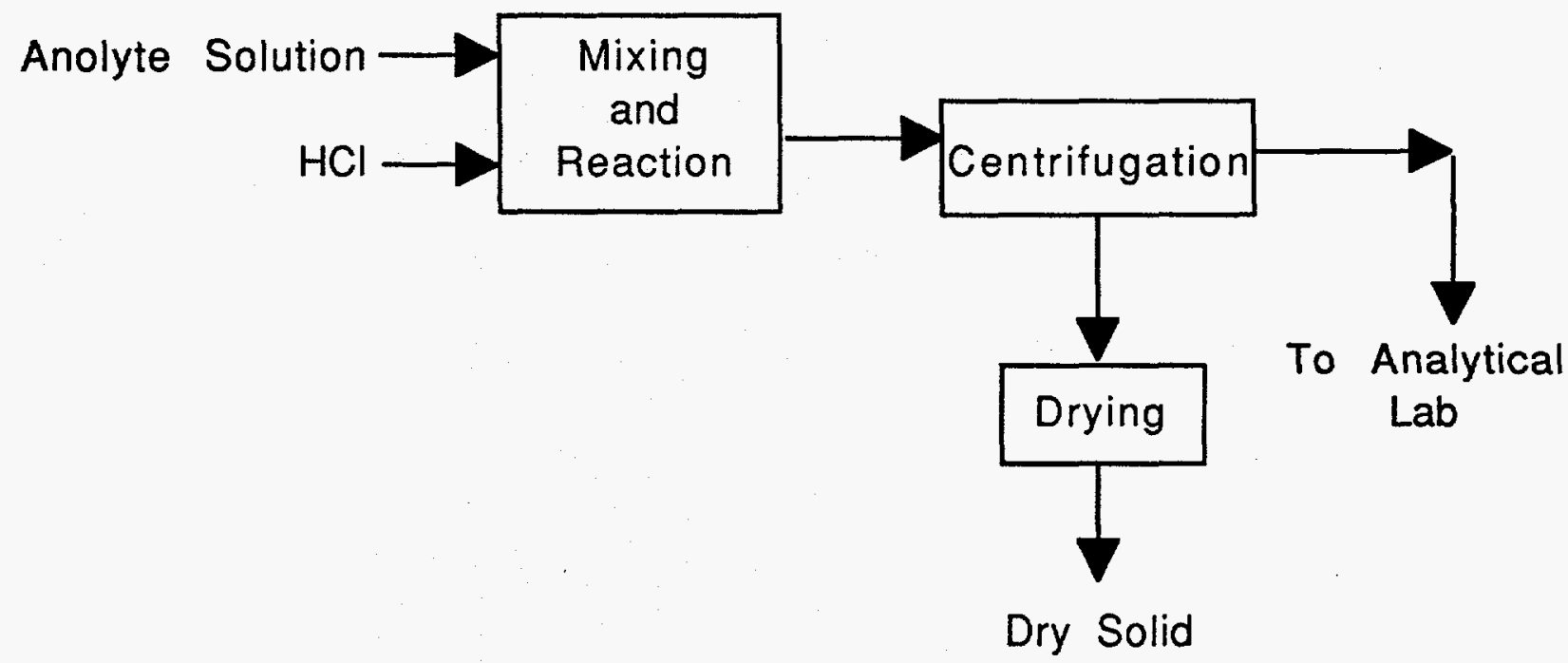

Anolyte solution $50 \mathrm{CC}$ was heated up to about $60^{\circ} \mathrm{C}$ under mixing before adding hydrochloric acid to the solution. The product, silver chloride, formed and precipitated. Mixing speed was maintained at about $400 \mathrm{rpm}$ to ensure a "just suspended" condition. The solution was mixed for 30 minutes before centrifuging and separating the silver chloride solids out from the solution. The solids were dried in an oven at $80^{\circ} \mathrm{C}$ overnight. The solution was sent to Analytical Laboratory for analysis of residual silver ions. The removal efficiencies were estimated based on the concentrations of silver ions before and after the reaction. 
III. Bench Scale Unit Description and Operation Procedure

As part of the process development, a bench scale unit was built to test the scaling effect of silver removal process. This unit utilized the existing equipment from bench scale silver recovery system (Reference 3). Fig. 2 shows the bench scale silver removal process.

Fig. 2 Bench Scale Ag Removal Unit

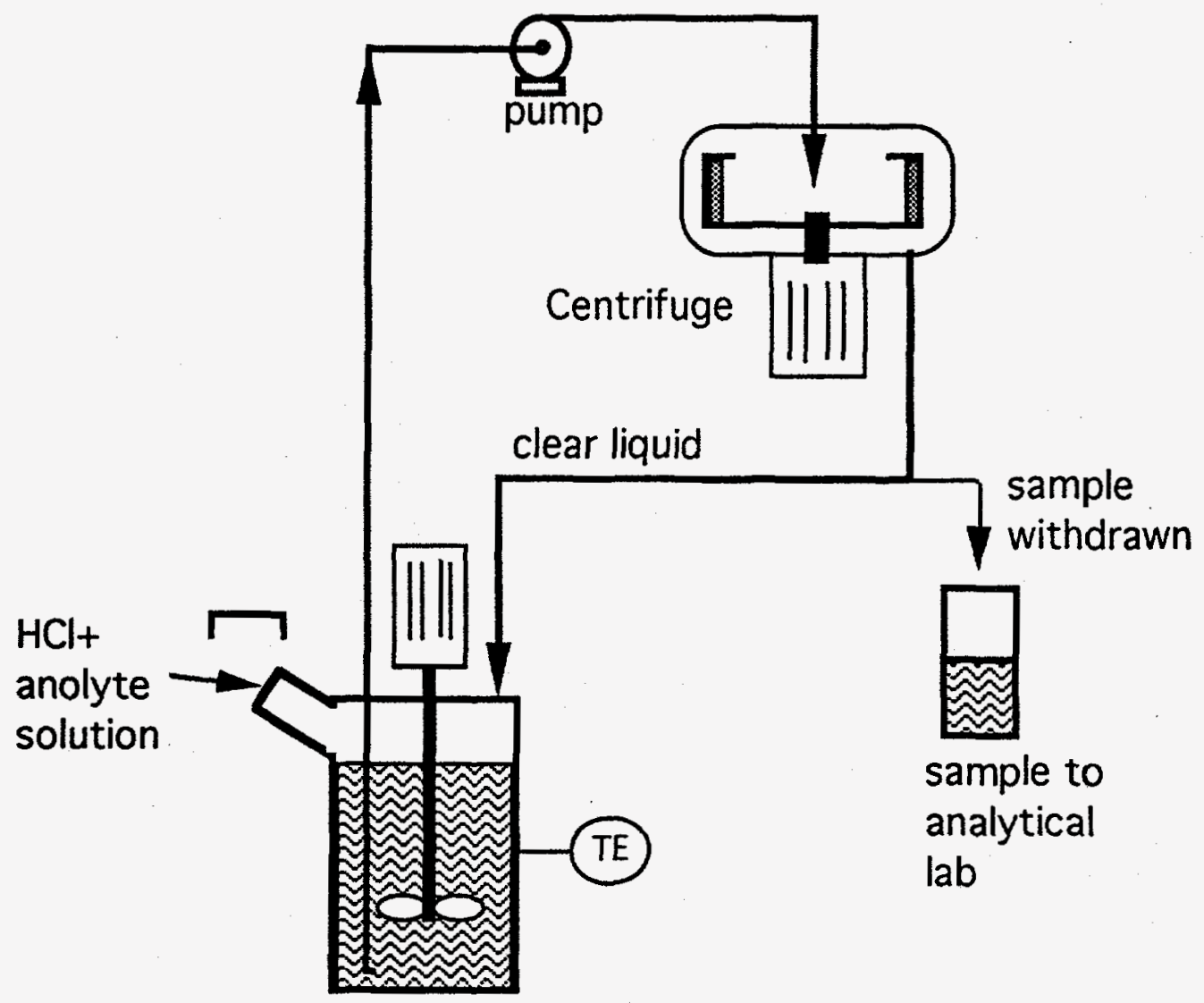

$\mathrm{AgCl}$ Precipitation

Tank (10 Liter)

The bench scale unit and its operation procedure are described as follows: 
1. Precipitation Tank

The precipitation tank was made of glass with volume of 10 liters. It was a cylindrical vat with a cover to prevent reaction medium from spilling out. A heating plate was used to heat up the solution to a desirable temperature range 50 to $60^{\circ} \mathrm{C}$. The solution temperatures were monitored by a thermometer. The transparent nature of the glass also allowed us to observe and adjust mixing conditions.

\section{Mixer}

The mixing speed was maintained at about $400 \mathrm{rpm}$ by a Variac to achieve a good mixing. The impeller width was 3 inch. The shaft was made of stainless steel to avoid corrosion.

\section{Pump}

A peristaltic pump was used to transfer slurry from the precipitation tank to a centrifuge. Pump capacities were from 1 to 5 liters per minute.

\section{Centrifuge}

The bowl volume of the centrifuge is 2 liters. The centrifuge's g-value is 500 and revolution is $1725 \mathrm{rpm}$.. The bowl was made of stainless steel.

\section{Sample Bottle}

Small sample bottles were used to take samples from the clear liquid return line. The samples were sent to Analytical Laboratory for analysis.

\section{Tubing and Fittings}

All the tubing is made of flexible polymers (Tygon) for the ease of operation. Fittings are made of Teflon and Kyner.

Anolyte solution $4000 \mathrm{~g}(3037 \mathrm{CC})$ was poured into the precipitation tank under mixing. The solution was then heated up to a desirable temperature range by a heating plate before adding $\mathrm{HCl}$ into the tank. Precisely measured amounts of hydrochloric acid were added in for about 45 seconds. Reaction was very fast and the product silver chloride formed. A thermometer was used to monitor the solution temperatures during the course of reaction. 
After a desired reaction time of 30 minutes was reached, the solution slurry was transferred to a centrifuge by a peristaltic pump at a rate of 2.5 liters $/ \mathrm{min}$. for solid-liquid separation. The solution recycled back to the tank and solids stayed in the centrifuge bowl. Several recycle passes were needed in order to achieve a good separation. Samples were taken from the clear liquid return line and then sent to the Analytical Laboratory for analysis of residual silver ions.

Table 1 shows the scales of lab scale unit, bench-scale unit and MWMF scale.

Table 1

System Amounts of Anolyte Treated Location Scale ratio

$\begin{array}{llll}\text { Lab Scale } & 50 \mathrm{CC} & \mathrm{B}-241 & 1\end{array}$

$\begin{array}{llll}\text { Bench-Scale } & 3.0 \text { liters } & \text { B-161 } & 60\end{array}$

$\begin{array}{llll}\text { Pilot-Plant } & 210 \text { liters } & \text { MWMF } & 4200\end{array}$

Table 1 shows that scale up ratios 60 from lab-scale to bench scale and 70 from bench scale to MWMF pilot scale, respectively. A successful operation of the bench scale unit would provide important design information to the MWMF pilot scale unit.

\section{Test Results}

\section{Removal Efficiencies at $1.0 \mathrm{X} \mathrm{HCl}$ Stoichiometry}

Since silver chloride is not soluble in anolyte solution, the stoichiometry of $\mathrm{HCl}$ required for removing silver ions from the solution should be close to 1 . Therefore a theoretical amount of $\mathrm{HCl}$ was used in the beginning to test the removal efficiencies for the lab scale and bench scale unit. The results are shown in Table 2. 
Table 2

System $\mathrm{HCl}$ Stoichi. Ag Conc., M Removal Residual AgCl in Before After Eff. Final Form**

Lab-scale $\quad 1.0 \mathrm{X} \mathrm{HCl} \quad 0.4926 \quad 6.14 \mathrm{E}-03 \quad 98.75 \% \quad 0.88 \%$ wt.

$\begin{array}{llllll}\text { BSP-1 } & 1.0 \times ~ H C l & 0.4056 & 1.78 \mathrm{E}-03 * & 99.56 \% & 0.36 \% \text { wt. }\end{array}$

* Sample taken at 21 minutes after starting the centrifuge or 10 recycle passes.

** Anolyte solution assumed to contain about $10 \%$ wt. dissolved ash before MEO cleanout.

Table 2 shows that, from both lab-scale and bench scale, silver removal efficiencies are good at $1.0 \mathrm{X} \mathrm{HCl}$ stoichiometry. The residual silver in the anolyte after the silver removal process will go to Final Forms with concentrations less than $1 \%$ wt.

2. Removal Efficiencies With Excess $\mathrm{HCl}$

To test the silver removal efficiencies with excess $\mathrm{HCl}$, two tests, namely, BSP-2 and BSP-3 were conducted and the results are tabulated in Table 3.

Table 3

Test $\mathrm{HCl}$ Stoichi. Ag Conc. $\mathrm{M}$ Removal Residual $\mathrm{AgCl}$ in

Before After Eff. Final Form

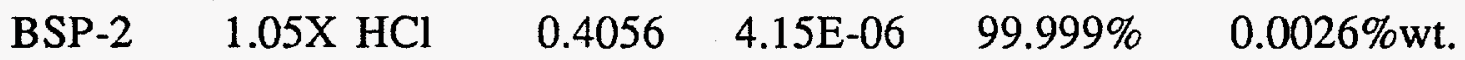
(5\% excess)

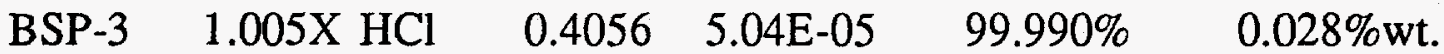
(0.5\% excess)

Table 3 shows that excellent silver removing efficiencies were achieved with a slightly excess $\mathrm{HCl}$. The result from test number BSP-3 indicates that the residual silver chloride going to Final Form can be as low as $0.028 \%$ wt with $0.5 \%$ excess $\mathrm{HCl}$. 


\section{Time of Centrifugation}

One of the objectives for the bench scale test is to determine how efficient a centrifuge can be when used for separating silver chloride from anolyte solution. Many samples were taken for the test BSP-3 during the centrifugation and the results are shown in Table 4.

Table 4 BSP-3 Centrifuge

\begin{tabular}{|c|c|c|c|c|}
\hline Time of & Recycle & Ag ion & Total Ag* & Residual $\mathrm{AgCl}$ \\
\hline Centrifuge & Passes & Conc., $\mathrm{M}$ & Conc. $\mathrm{M}$ & in Final Form \\
\hline $7 \mathrm{~min}$. & 3.5 & $5.04 \mathrm{E}-05$ & $19.10 \mathrm{E}-05$ & $280 \mathrm{ppm}(0.028 \%)$ \\
\hline 14 & 7.0 & 5.07E-05 & $9.89 \mathrm{E}-05$ & $144 \mathrm{ppm}$ \\
\hline 21 & 10.5 & $4.64 E-05$ & $9.09 \mathrm{E}-05$ & $132 \mathrm{ppm}$ \\
\hline 58 & 29.0 & $3.34 \mathrm{E}-05$ & $6.53 \mathrm{E}-05$ & $95 \mathrm{ppm}$ \\
\hline 70 & 35.0 & $3.20 \mathrm{E}-05$ & $4.64 \mathrm{E}-05$ & $68 \mathrm{ppm}$ \\
\hline
\end{tabular}

* Total $\mathrm{Ag}$ includes silver ions and tiny $\mathrm{AgCl}$ particles suspended in solution.

Table 4 shows that centrifugation is very effective for separating $\mathrm{AgCl}$ particles out from the solution. The residuals $\mathrm{AgCl}$ concentration is only $0.00019 \mathrm{M}$ after 3.5 recycle passes.

\section{Optimal Condition}

Fig. 3 shows the Ag content in the residual solids sent to Final Forms. Overlaid on the same plot is the resulting $\mathrm{pH}$ of the waste water distillate sent to Water Treatment. As more excess $\mathrm{HCl}$ is used in the clean-out operation the $\mathrm{Ag}$ content of the solid residues sent to Final Forms is reduced, but the $\mathrm{pH}$ of the resulting distillate water sent to Water Treatment is also lowered. If the distillate water $\mathrm{pH}$ gets below about 2 the resulting salt content after neutralization is too high to directly sewer and the water must be treated to remove the salt. It is therefore desirable to use no more than $0.02 \%$ excess $\mathrm{HCl}$ ( $\mathrm{pH}>3$ waste water) unless the resulting $\mathrm{Ag}$ level of approximately $0.35 \%$ wt in the residue solids is too high for Final Forms to handle comfortably. In that event the $\mathrm{HCl}$ concentration can be increased to lower the $\mathrm{Ag}$ with the resulting penalty that Water Treatment will need to reduce the salt content of the water before it can be sewered. This is not a very sever penalty since cleanouts occur at intervals of greater than 312 hours operating time at the maximum solids 
content in the feed of $5 \%$ of the organics loading. This is determined as follows:

$$
\begin{aligned}
& \mathrm{t}=(60 \mathrm{~L})(1.3 \mathrm{~kg} / \mathrm{L})(0.1 \mathrm{~kg} \text { solid } / \mathrm{kg} \text { anolyte })(20 \mathrm{~kg} \text { organic } / \mathrm{kg} \\
& \text { solid }) /(0.5 \mathrm{~kg} / \mathrm{h})=312 \mathrm{hr} \\
& \text { vol anolyte }=60 \mathrm{~L} \text { (estimated) } \\
& \text { anolyte density }=1.3 \text { (assume } 10 \mathrm{M}) \\
& \text { solids loading of anolyte }=0.1 \\
& 20 \mathrm{~kg} \text { organic } / \mathrm{kg} \text { solid }=\text { max loading of dirt in feed } \\
& 0.5 \mathrm{~kg} / \mathrm{h}=\text { max. organic feed rate }
\end{aligned}
$$

For cleaner feeds, or if dirty anolyte is integrated up to $400 \mathrm{~L}$ in the still feed tanks, this time can be extended into the thousands of hours.

Over the same $312 \mathrm{hrs}$, approximately $156 \mathrm{~L}$ of water will be produced at a minimum (10x this amount could be produced for highly aqueous feeds). The $60 \mathrm{~L}$ of anolyte, when distilled to $13 \mathrm{M}$ $\mathrm{HNO}_{3}$ and water will yield approximate $13 \mathrm{~L}$ of waste water. Thus the yield of low $\mathrm{pH}$ water will be at most $8.3 \%$ of the total waste water produced by MEO. In practice, this will be much lower, since most feeds will not possess all of the extreme properties assumed above.

The $\mathrm{pH}$ of the waste water is determined as follows:

$$
\begin{aligned}
& \mathrm{pH}=-\log \{(0.5 \mathrm{M}-\mathrm{Ag} / \mathrm{L})(1 \mathrm{M} \mathrm{HCl} / \mathrm{M}-\mathrm{Ag})(0.005 \text { excess }) /(0.22 \\
&\mathrm{distillate} / \text { anolyte ratio })\}
\end{aligned}
$$

anolyte $\mathrm{Ag}$ content $=0.5 \mathrm{M}-\mathrm{Ag} / \mathrm{L}$

excess $\mathrm{HCl}$ used $=0.5 \%$ (assumed for example)

waste water to anolyte ratio $=0.22$ (assume $10 \mathrm{M}$ anolyte)

The results of this computation for various excess quantities of $\mathrm{HCl}$ are shown in Fig's $3 \& 4$. The use of Fig's $3 \& 4$ allow the operator to select the output of $\mathrm{Ag}$ to Final Forms and the resulting $\mathrm{pH}$ of the waste water, depending upon the requirements of each for the specific waste stream. 


\section{Reagent . Requirement}

The only reagent required for the silver removal process is $\mathrm{HCl}$ which is inexpensive.

\section{Conclusions}

The silver removal process during the MEO cleanout has been successfully developed in the lab-scale and bench scale. High silver removal efficiency has been achieved using $\mathrm{HCl}$ as the percipitating reagent. Centrifugation has been demonstrated as an excellent way to separate $\mathrm{AgCl}$ particles from the anolyte solution. Hydrochloric acid is the only reagent required for the process. The trade-off between $\mathrm{Ag}$ going to Final Forms in the solid residues and $\mathrm{HCl}$ going into the waste water has been determined and data is provided to make a quantitative selection. The results from this process development provide a very useful information for the design and operation of the MEO process. 


\section{Ag cleanout data for MEO,}

assuming $10 \%$ dissolved solid loading in anolyte at cleanout time.

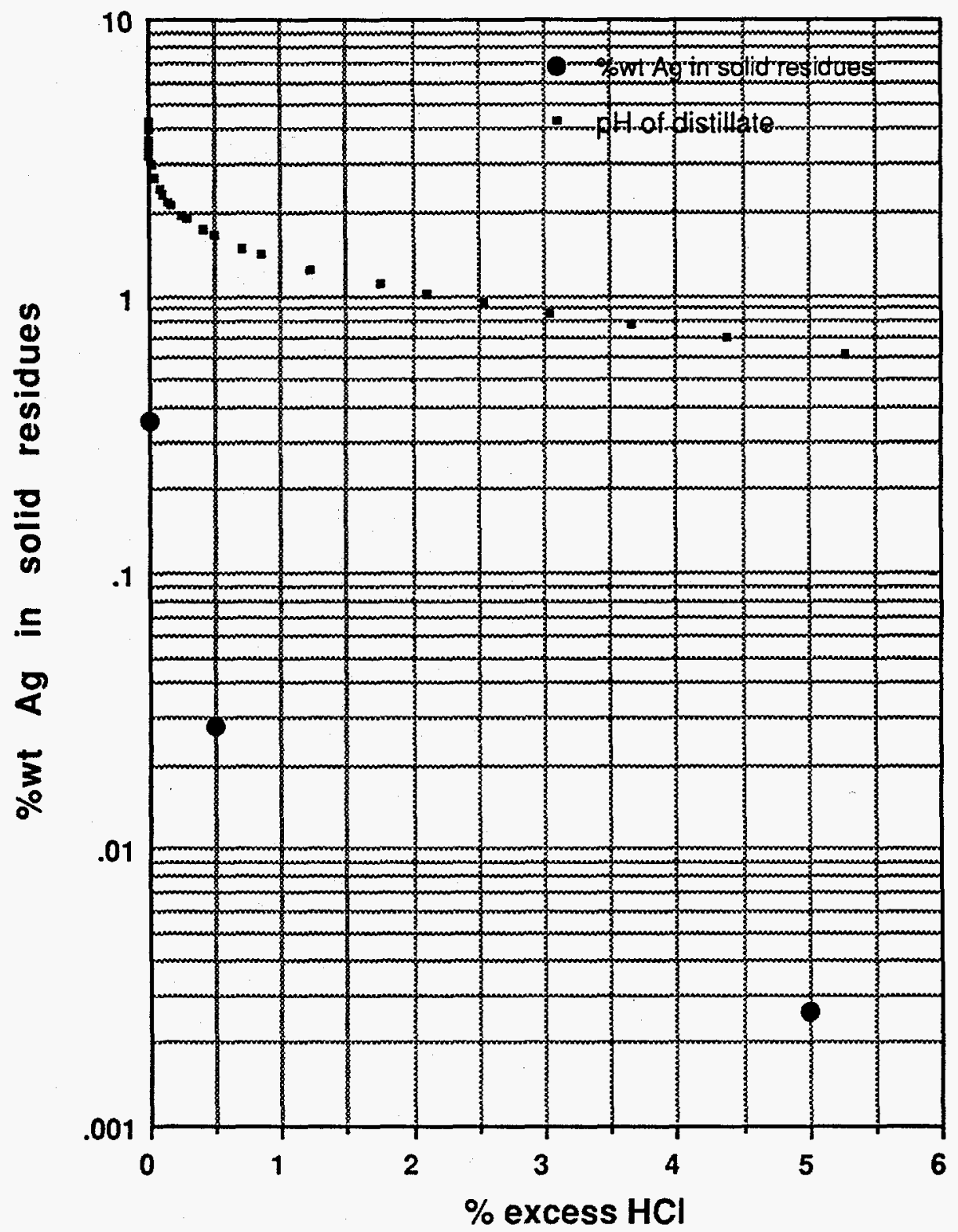

Fig. 3 - Showing the residual silver content in solids sent to Final Forms as a function of the excess $\mathrm{HCl}$ used in the clean-out operation. Also shown is the estimated $\mathrm{pH}$ of the resulting water distillate sent to Water Treatment as a result of the $\mathrm{HCl}$ (assume $0.5 \mathrm{M} \mathrm{Ag}$ to remove). The estimate of $\mathrm{pH}$ assumes anolyte of $10 \mathrm{M} \mathrm{HNO}_{3}$ split into pure water and $13 \mathrm{M} \mathrm{HNO} 3$ with all $\mathrm{HCl}$ going to the water phase. The water volume is about $22 \%$ of the anolyte original anolyte. 
Ag cleanout data for MEO, assuming $10 \%$ dissolved solid

loading in anolyte at cleanout time.

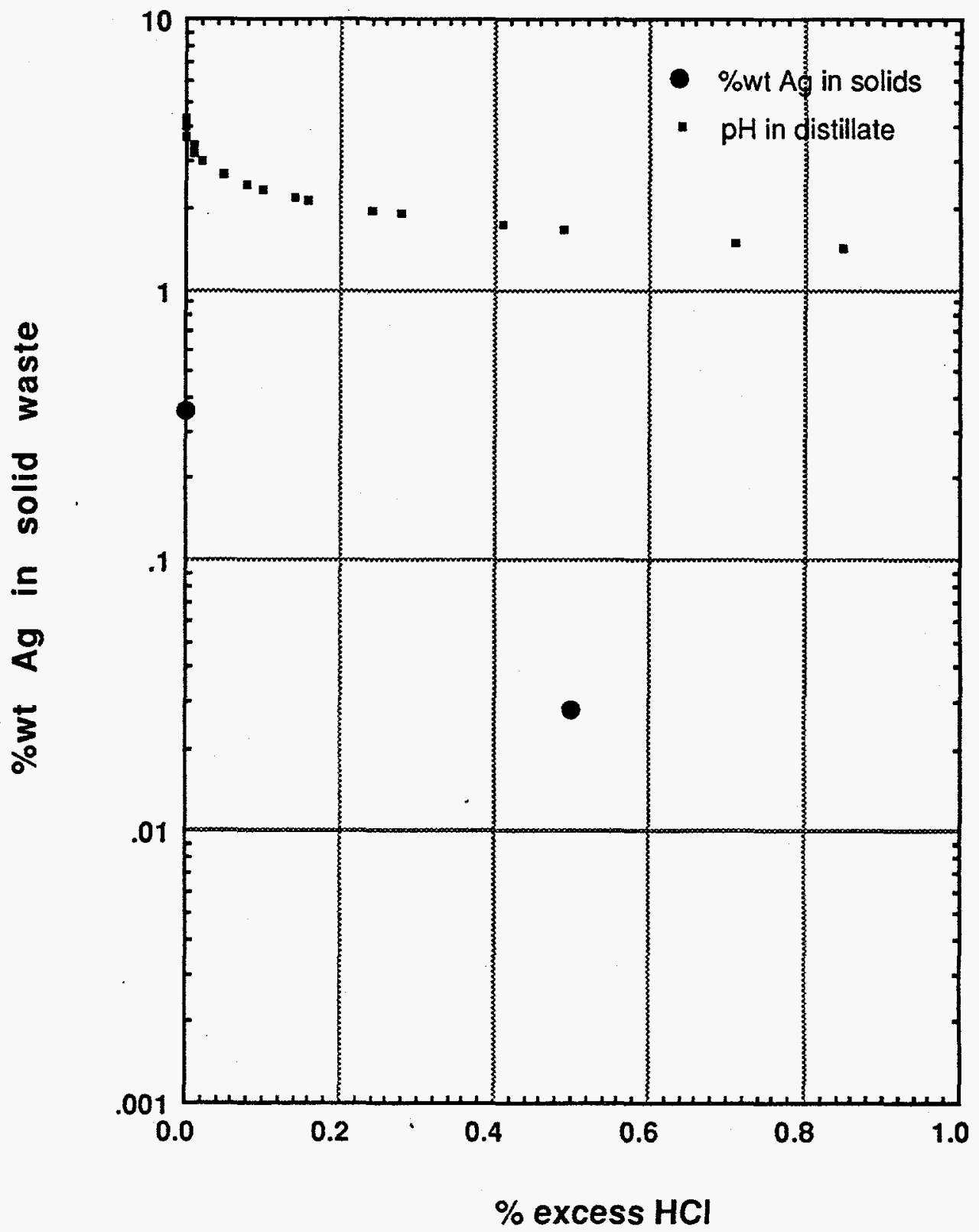

Fig. 4 - Same as Fig. 3 except scale expanded to show the o to $1 \%$ excess $\mathrm{HCl}$ region. 


\section{References}

1. "Mixed Waste Management Facility Conceptual Design Report", UCRL-PROP-116761, L-17293-1, April, 1994.

2. Per Conversation with Bob Hopper in June 1995.

3. Peter C. Hsu, Zoher Chiba, and Bruce Schumacher, "Bench Scale Silver Recovery for MEO System", L-19707-1, WBS 1.5.1.3.1, June 1995. 